\title{
Variation of bacterial communities along the vertical gradient in Lake Issyk Kul, Kyrgyzstan
}

\author{
Keilor Rojas-Jimenez, (1) ${ }^{1}$ Alex Araya-Lobo, ${ }^{1}$ \\ Fabio Quesada-Perez, ${ }^{1}$ Johana Akerman-Sanchez, ${ }^{1}$ \\ Brayan Delgado-Duran, ${ }^{1}$ Lars Ganzert, ${ }^{2,3,4}$ \\ Peter O. Zavialov, ${ }^{5}$ Salmor Alymkulov, ${ }^{6}$ \\ Georgiy Kirillin ${ }^{7}$ and Hans-Peter Grossart (1) $^{2,8^{*}}$ \\ ${ }^{1}$ Escuela de Biología, Universidad de Costa Rica, San \\ José, 11501, Costa Rica. \\ ${ }^{2}$ Department of Experimental Limnology, Leibniz-Institute \\ of Freshwater Ecology and Inland Fisheries, Alte \\ Fischerhuette 2, Stechlin, D-16775, Germany. \\ ${ }^{3}$ GFZ German Research Centre for Geosciences, \\ Helmholtz Centre Potsdam, Section 3.7 \\ Geomicrobiology, Telegrafenberg C-422, Potsdam, \\ 14473, Germany. \\ ${ }^{4}$ University of Goettingen, Experimental Phycology and \\ Culture Collection of Algae (EPSAG), Nikolausberger \\ Weg 18, Goettingen, 37073, Germany. \\ ${ }^{5}$ Shirshov Institute of Oceanology, Moscow, 117997, \\ Russia. \\ ${ }^{6}$ Institute of Physics, National Academy of Sciences of \\ Kyrgyz Republic, Chui Avenue, 265-a, Bishkek, 720071, \\ Kyrgyzstan. \\ ${ }^{7}$ Department of Ecohydrology, Leibniz-Institute of \\ Freshwater Ecology and Inland Fisheries, \\ Müggelseedamm 310, Berlin, D-12587, Germany. \\ ${ }^{8}$ Institute for Biochemistry and Biology, Potsdam \\ University, Maulbeerallee 2, Potsdam, 14469, Germany.
}

\section{Summary}

We explored the diversity and community composition of bacteria along a vertical gradient in Lake Issyk Kul, Kyrgyzstan, one of the world's largest and deepest brackish lakes. We identified 4904 bacterial amplicon sequence variants based on the 16S rRNA gene analysis and determined significant changes in the composition, responding mainly to depth and salinity. A higher abundance of Proteobacteria and Bacteroidetes was observed in the surface waters

Received 6 November, 2020; accepted 29 January, 2021. **For correspondence. E-mail hgrossart@igb-berlin.de; Tel. ++49 (0)33082 69991; Fax. ++49 (0)33082 69917. and lake tributaries. Cyanobacteria were more abundant in the deep chlorophyll maximum from 28.5 to $128 \mathrm{~m}$, while Planctomycetes and Chloroflexi were dominant in the deepest layers, from 128 to $600 \mathrm{~m}$. According to our machine learning analyses, depth and temperature were the most critical environmental factors, with strong effects on Proteobacteria, Planctomycetes and Chloroflexi, while oxygen was associated with the variations in Cyanobacteria. We also observed that with increasing depth, the alpha diversity values increased. The dominance of Planctomycetes and Chloroflexi in the deepest layers can only be seen in a few lakes of the world. However, the lake is facing increasing anthropogenic and climatic pressure. There is an urgent need to understand better the ecological role and function of these unique deep-water microbial communities.

\section{Introduction}

The current knowledge about the distribution of planktonic bacterial communities along the vertical gradient in lake ecosystems is limited, particularly in deep lakes. Of the approximately 117 million lakes with surface areas greater than $0.002 \mathrm{~km}^{2}$ that exist globally, only 36 have mesopelagic ecosystems with maximum depths greater than $400 \mathrm{~m}$ (Verpoorter et al., 2014; Dodds and Whiles, 2020). Of these, only a handful has been studied concerning diversity and composition of their microbial communities, with examples mainly from Lake Baikal in Russia (Glöckner et al., 2000; Bel'kova et al., 2003; Kurilkina et al., 2016), Lake Tanganyika in Africa (De Wever et al., 2005) and Crater Lake in the United States (Urbach et al., 2001).

Water depth is one of the main factors influencing bacterial communities' composition and distribution in both oceans and lakes. Along the vertical gradient, there is a transition from the photic to the aphotic zone, which also includes a decrease in temperature, oxygen and nutrients, concomitant with an increase in hydrostatic pressure (DeLong et al., 2006; Bryant et al., 2012; Garcia et al., 2013; Mende et al., 2017; Wu et al., 2019). Salinity 
is another major factor that influences the composition of microbial communities in aquatic ecosystems in both vertical and horizontal gradients (Herlemann et al., 2011; Newton et al., 2011; Tang et al., 2012, 2015; RojasJimenez et al., 2019).

Lake Issyk Kul is located in the northeast of Kyrgyzstan and has the singularity of being one of the largest and deepest lakes in Central Asia and worldwide. This lake arouses great scientific interest because of its geophysical and ecological characteristics. Being the sixth deepest lake in the world and tenth-largest by volume, it reveals surprisingly high rates (below 11 years) of deepwater renewal (Hofer et al., 2002; Peeters et al., 2003), which maintain the lake water column well-oxygenated down to its deepest parts (Zavialov et al., 2018). Despite the absence of any outflows, the lake water's salinity of $6 \mathrm{~g} / \mathrm{kg}$ is relatively low, suggesting the lake to become endorheic relatively recently, possibly due to tectonic processes (Romanovsky, 2002).

Lake Issyk Kul is (ultra)-oligotrophic with highly transparent water, reaching Secchi depths of more than $20 \mathrm{~m}$. The low nutrients content in the surface waters and the high amount of solar radiation penetrating deep into the water column create a unique environment characterized by a maximum of photosynthesis at depths of $30-40 \mathrm{~m}$. First systematic studies on Lake Issyk Kul date back to the 1920s. It was one of the most studied lakes in the 1960-80s but research stopped abruptly after the Soviet Union's collapse. During the 1960-80s, the lake ecosystem experienced a substantial impact by human activities, including the introduction of non-native commercial fish species displacing the endemic species, the input of wastewater and pollution by industry and agriculture, with effects on the aquatic ecosystem that remain unknown (Savvaitova and Petr, 1992; Giralt et al., 2004; Baetov, 2005). Yet, almost nothing is known about microbial communities, particularly heterotrophic bacteria at the base of the aquatic food web.

In this work, we used high-throughput sequencing of the V4-V5 region of the 16S rRNA gene to provide a more in-depth insight into the taxonomic composition and vertical distribution of bacterial communities inhabiting Lake Issyk Kul (Fig. 1). We complemented the analysis with the use of Machine Learning tools, which are helpful to reveal unexpected biological patterns, discover ecological relationships between microorganisms and their environment and formulate new biological hypotheses (Eraslan et al., 2019; Qu et al., 2019). Considering that this is a unique deep-water brackish lake, exhibiting aerobic conditions throughout the entire depth gradient, we particularly aimed to determine how community composition varies along the depth gradient and which particular environmental variables may be responsible for those changes. We hypothesize that depth and its related environmental variables such as sunlight accessibility, hydrostatic pressure, temperature and salinity will lead to the formation of different layers, each one dominated by specific bacterial communities.

\section{Results}

We observed pronounced changes in the composition of the bacterial communities of Lake Issyk Kul along the vertical gradient, responding mainly to the variables depth and salinity (Fig. 2). In total, 4904 bacterial ASVs were identified, whereby the phylum Proteobacteria was the most abundant, representing, on average, $28.5 \%$ of all sequences. In lower average proportions, other groups were also detected, such as Bacteroidetes (16.8\%), Cyanobacteria (14.8\%), Planctomycetes (12.85\%), Actinobacteria (9.8\%), Verrucomicrobia (8.7\%) and Chloroflexi (6.7\%) (Suppl. Fig. 2).

\section{Differences in bacterial communities according to depth}

We used the K-means algorithm to create clusters of samples according to depths, distinguishing four layers: 0 to $28.5,28.5$ to 128,128 to 402 and 402 to $600 \mathrm{~m}$. Another cluster included the tributary rivers. This grouping was consistent with differences observed in their bacterial composition (Fig. 2A). At the phylum level, a higher abundance of Proteobacteria and Bacteroidetes was found in the lake's surface waters and the river samples. In the DCM (between 28.5 and $128 \mathrm{~m}$ ), there was a higher abundance of Cyanobacteria, while Planctomycetes and Chloroflexi became more abundant at greater depth, i.e. between 128 and $600 \mathrm{~m}$.

At the ASV level, a strain associated with the genus Sphingomonas (Alphaproteobacteria) was the most abundant in the rivers. Cyanobium (Cyanobacteria), Loktanella (Alphaproteobacteria) and an unknown strain of Burkholderiaceae (recently reclassified within Gammaproteobacteria) were the most abundant in the surface waters of the lake. Cyanobium also dominated in the DCM between 28.5 and $128 \mathrm{~m}$. Three strains related to families Anaerolineaceae (Chloroflexi) as well as Phycisphaeraceae and Gimesiaceae (Planctomycetes) were the most abundant ASVs in the deep layers (128-402 and 402-600 m) although with small differences between each layer.

The observed variation in the composition of bacterial communities along the depth gradient was consistent with the NMDS analysis that showed a clear separation of the clusters (Fig. 3A). These results were also compatible with the PERMANOVA analysis, showing statistically significant differences between the rivers and the lake's bacterial communities, and even within each of the four depth clusters identified (Suppl. Table 2). 


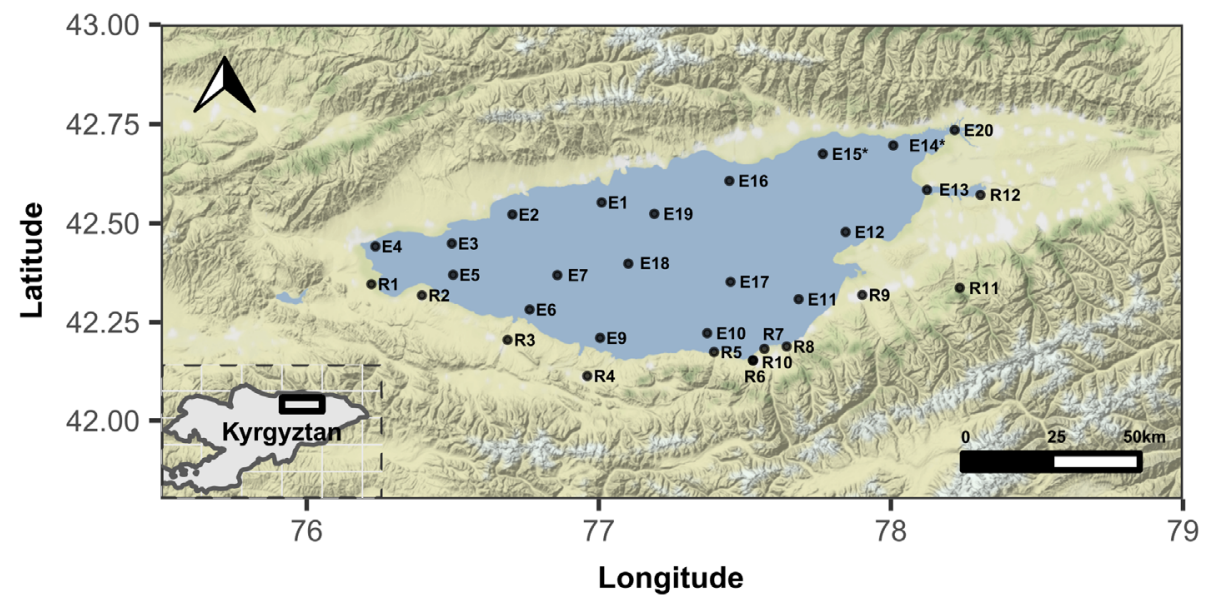

Fig 1. Location of sampling points in Lake Issyk Kul, Kyrgyzstan, and some of its tributary rivers. We set 19 sampling points in the lake (indicated with the letter E) and 12 tributaries (indicated with the letter R). In total, we analysed 43 water samples from the lake and 12 from the tributaries. The locations marked with an asterisk (E14 and E15) were sampled but discarded during the data analysis stage due to low sequencing depth.
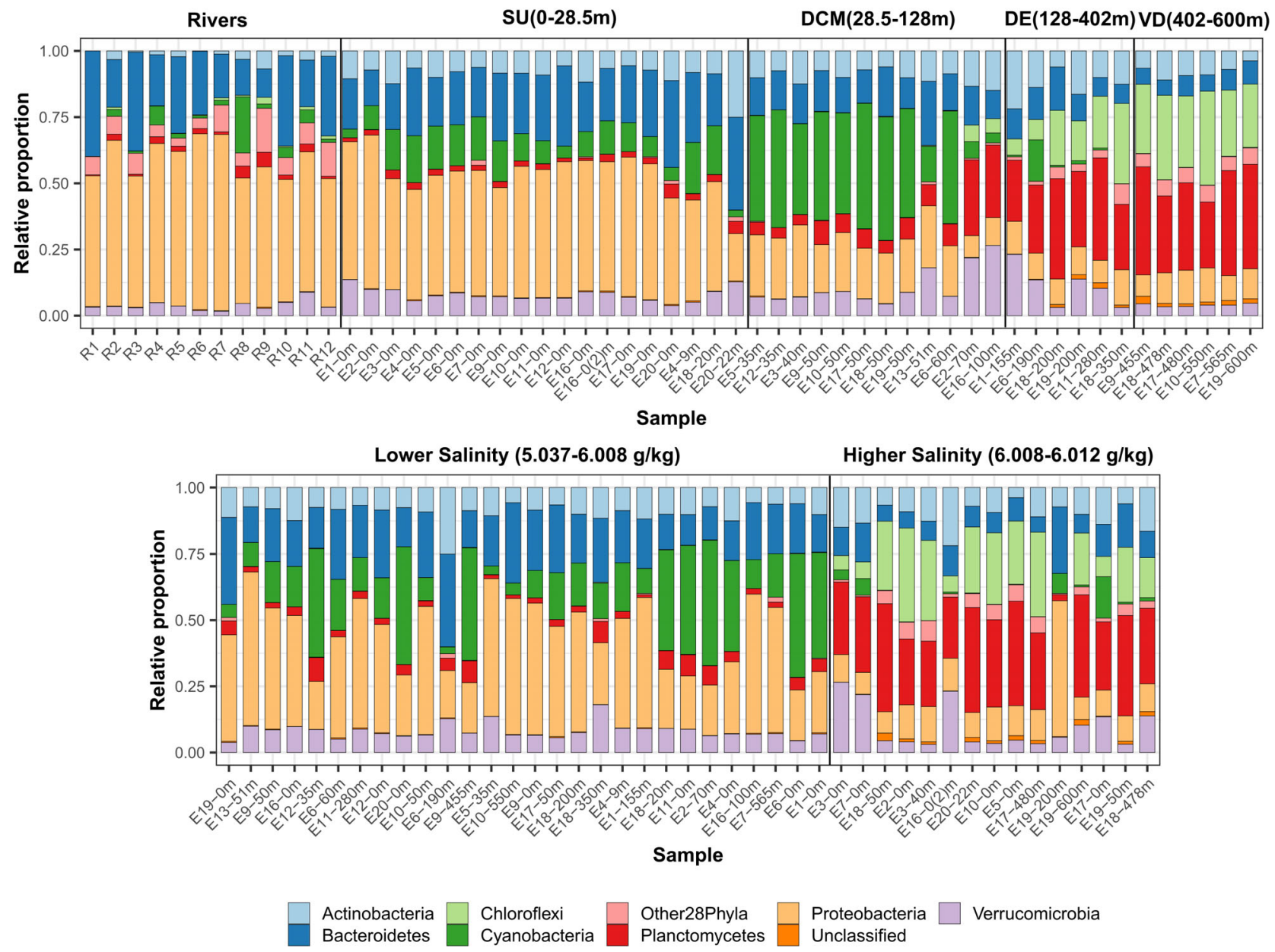

Fig 2. The relative abundance of bacteria, determined at the phylum's taxonomic level, in water samples of Lake Issyk Kul, Kyrgyzstan. Panel A shows the results grouped by depth clusters, while panel B shows them sorted by salinity. SU: surface, DCM: deep chlorophyll maximum, DE: deep layer, VD: very deep layer. 

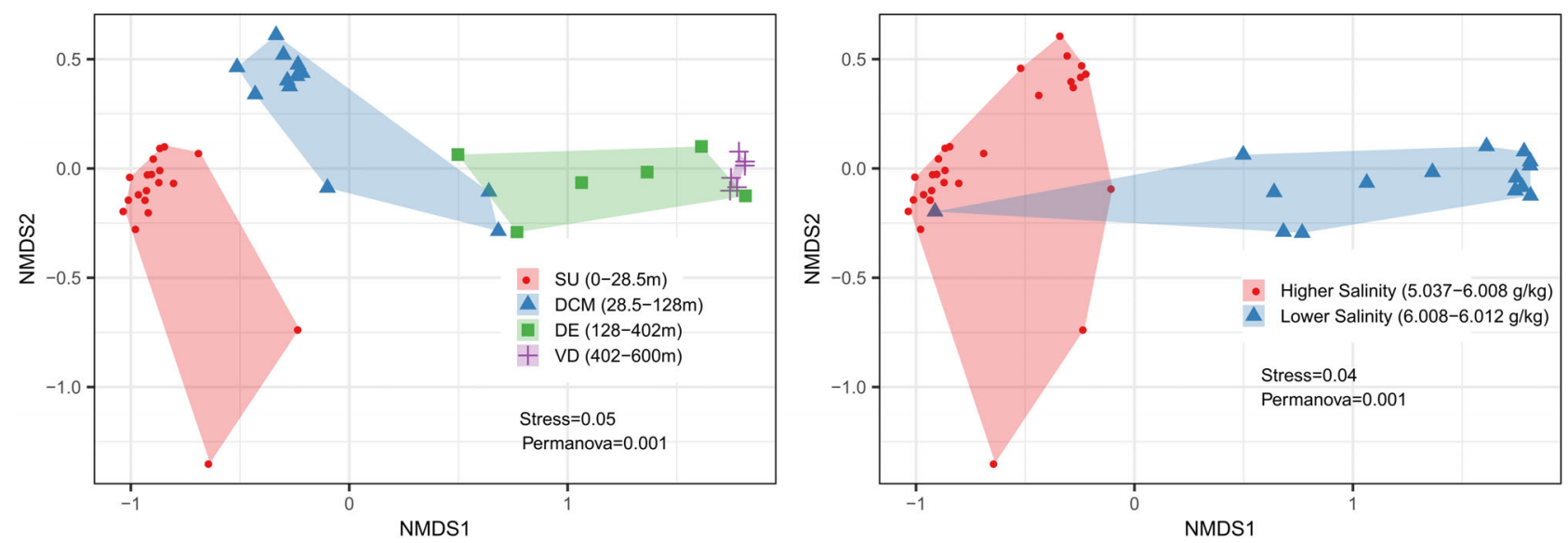

Fig 3. Non-metric multidimensional scaling analyses of the bacterial communities in Lake Issyk Kul. Panel A shows the clusters by depth, while panel B for salinity. Stress values and $p$-value of the PERMANOVA are shown. SU: surface, DCM: deep chlorophyll maximum, DE: deep layer, VD: very deep layer.

\section{Differences in bacterial communities according to salinity}

We also observed differences in the composition of bacterial communities, according to salinity (Fig. 2B). In superficial layers, salinity ranged between 5.037 and $6.008 \mathrm{~g} \mathrm{~kg}^{-1}$, where a higher abundance of Proteobacteria, Cyanobacteria and Bacteroidetes was observed. The river samples were not included in this analysis because the information on salinity was not recorded. Salinity was more stable in the deeper layers, between 6.008 and $6.012 \mathrm{~g} \mathrm{~kg}^{-1}$, where a higher relative abundance of Planctomycetes and Chloroflexi was observed. These differences in community composition were consistent with the clustering of the NMDS analysis (Fig. 3B) and the PERMANOVA analysis, showing significant differences in the composition between these two salinity layers (Suppl. Table 2). Regarding other environmental parameters (such as oxygen or temperature), we did not find any significant effect on the lake bacterial community composition.

\section{Effects of environmental variables on alpha diversity values}

As a complementary method, we used machine learning (Random Forest algorithm) to identify environmental variables with more weight in the observed variation of the relative abundance of the bacterial phyla (Fig. 4). According to this analysis, depth and temperature are the environmental factors that have the most substantial effect on the variations in Proteobacteria, Planctomycetes and Chloroflexi. The higher abundance of Cyanobacteria was associated with high oxygen conditions, while for Actinobacteria and Verrucomicrobia, no specific variables were distinguished as being responsible for the variations in their abundance.

The richness, estimated at the taxonomic level of family, ranged between 75 and 342 per sample. The factor that best explained this variability was depth (Random Forest; $p=0.001, R^{2}=0.708$, Fig. $5 \mathrm{~A}$ ). We observed an increase in richness with increasing depth, ranging from $110 \pm 7$ bacterial families in surface waters to $309 \pm 6$ in the deepest layers (Fig. 5B). The variation in richness between layers was statistically significant (Kruskal-Wallis, $H=35.52, p<0.001$ ), but according to the generalized additive models (GAM), there was stabilization in the number of families at $280 \mathrm{~m}$ (GAM; $R^{2}=0.827$, $F=41.89, p<0.001$, Fig. $5 \mathrm{C}$ ). At lower temperatures, consistent with greater depths, we also observed an increase in richness (Fig. 5D and E).

The percentage of oxygen $\left(\mathrm{O}_{2} \%\right)$ was a factor that also explained the variability in the richness (Random Forest; $p=0.001, R^{2}=0.403$, Fig. 5F). Although Lake Issyk Kul presents aerobic conditions along the vertical gradient (Supplementary Fig. 3), higher richness values were determined in the layers where oxygen was lower $(73.6 \%-91.3 \%)$. In comparison, values were lower in the superficial and DCM layers, where oxygen content is higher (91.3\%-177.1\%). Therefore, we observed a slight decrease in richness as the oxygen level increases (GAM; $R^{2}=0.625, F=29.34, p<0.001$, Fig. 5G).

\section{Discussion}

The main finding was that depth plays a decisive role in the variations of bacterial communities in this deep lake. Four layers were distinguished along the depth gradient-each layer with a set of particular environmental conditions and a community structure significantly 

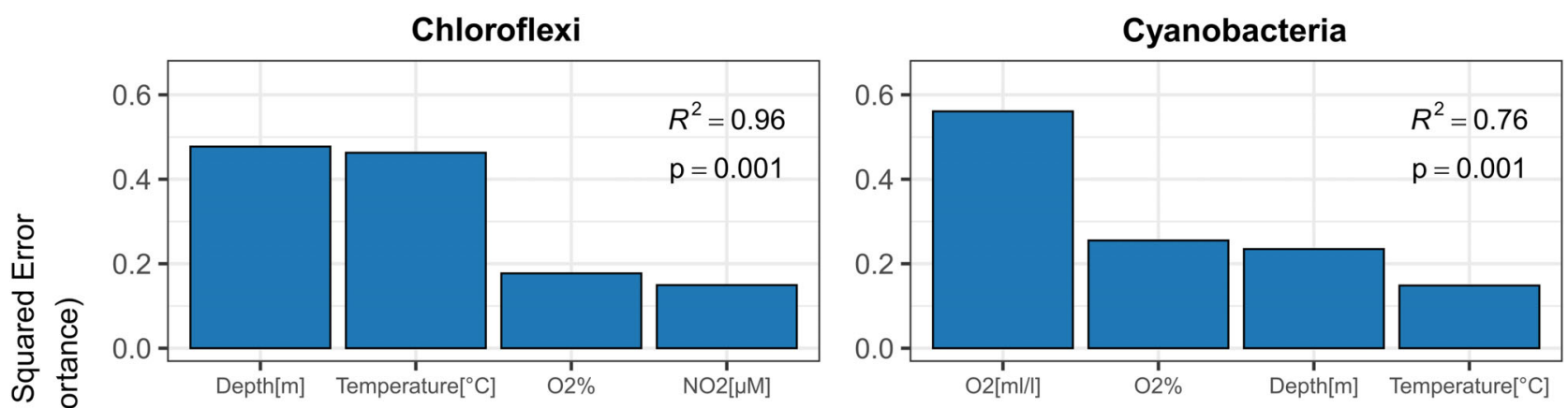

Planctomycetes

Proteobacteria
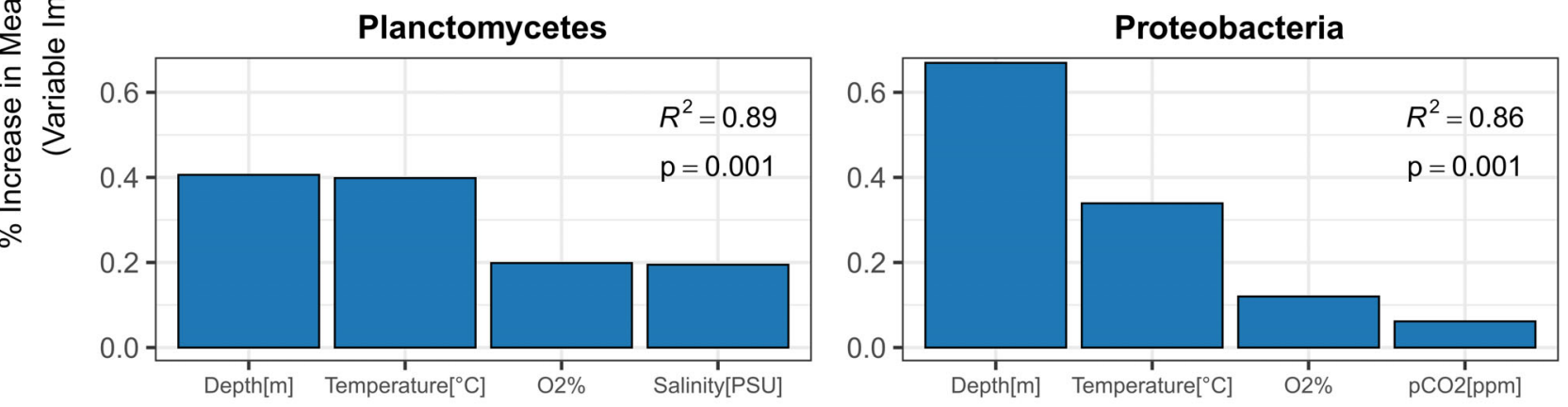

Environmental Variables

Fig 4. Main environmental factors associated with variations in the abundance of four phyla of bacteria in Lake Issyk Kul. The analyses were performed using Random Forest and considering the most abundant bacterial groups per depth layer. Results are shown for Chloroflexi (A), Cyanobacteria (B), Planctomycetes (C) and Proteobacteria (D).

different from each other. In general, these results are consistent with those obtained in other deep lakes such as Lake Baikal in Russia, Crater Lake in the United States and Lake Tanganyika in Central Africa, which also show the differentiation of bacterial communities along the depth profile, although each of the bacterial communities in the respective lakes was responding to different physicochemical conditions (Glöckner et al., 2000; Urbach et al., 2001; Bel'kova et al., 2003; De Wever et al., 2005; Kurilkina et al., 2016). However, Lake Issyk Kul showed differences in the composition of the most abundant groups in the different depth layers, which are probably related to this lake's particular conditions, such as having brackish waters and high oxygenation.

The composition of the bacterial communities in the tributaries was significantly different from that found in the lake's different layers, including the surface layer. For example, Sphingomonas was the most abundant genus in the rivers while Loktanella and an unknown Burkholderiaceae were the most abundant in the lake's surface layer. Also, Cyanobacteria, Planctomycetes and Verrucomicrobia were almost missing in these mountain rivers characterized by high turbulence and often high sediment load, as previously reported (Wilhelm et al., 2013; Peter and Sommaruga, 2016). Although this work was not designed to determine the role of tributaries in providing seed communities for the lake, the results showed clear differences between these two ecosystems. It will be important to determine further how the lake water layers' unique conditions, including the residence time, the availability of nutrients and the light regime, exert a filtering effect for bacterial taxa's lateral inputs.

With the increase in depth and slightly more saline conditions, we observed a decrease in the abundance of Proteobacteria, which is consistent with previous studies showing the effects of these environmental variables on the abundance of this phylum (Simon et al., 1999; Cottrell and Kirchman, 2003; Kirchman et al., 2005; Kan et al., 2008). The DCM was dominated by picoplanktonic unicellular cyanobacteria, particularly of the genus Cyanobium, as previously reported in other oligotrophic lakes in Europe (Padisák et al., 2003, 2004; Callieri, 2008; Selmeczy et al., 2016). A DCM at $\sim 50 \mathrm{~m}$ depth, which is significantly more profound than in any reported lake, might result from extremely high subsurface radiation in parallel to the high water transparency and low nutrients, which is concurrent with a maximum concentration of oxygen and chlorophyll-a (Suppl. Fig. 3).

We show the predominance of Anaerolineaceae (Chloroflexi) and two families of Planctomycetes (Phycisphaeraceae and Gimesiaceae) in the deeper layers of a lake. Other studies have also reported the presence (but not dominance) of these groups in deep 

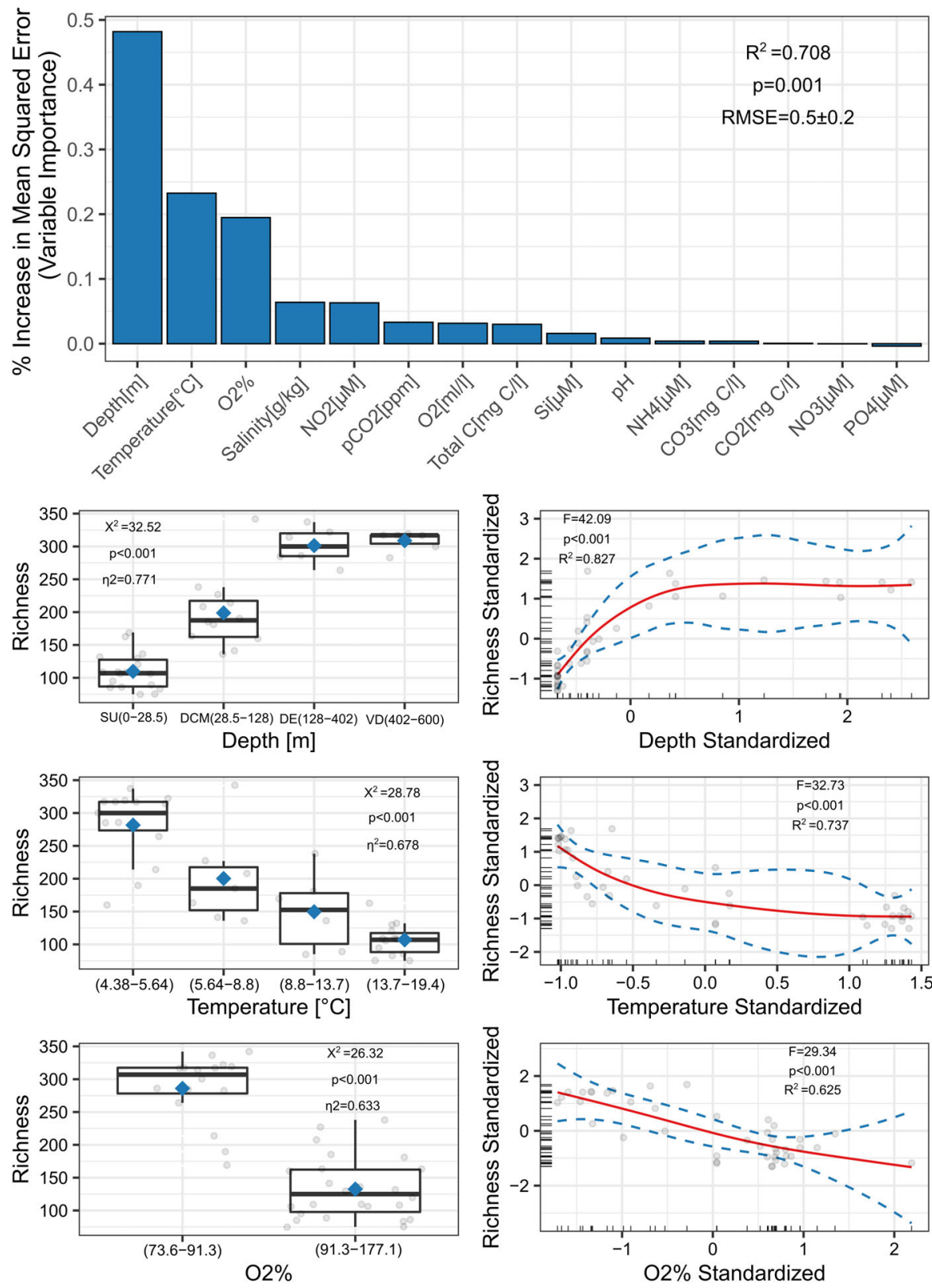

Fig 5. Main environmental variables associated with variations in the richness values in Lake Issyk Kul. Analyses were performed at the taxonomic level of family using Random Forest. Panel A shows the importance of variables. Panels B, D and F show boxplots of richness estimations according to bins (value intervals) of the leading environmental factors (Depth, Temperature and $\mathrm{O}_{2} \%$ respectively). The standardized values considering the GAM model predicted relationships are shown in panels C, E and G. SU: surface, DCM: deep chlorophyll maximum, DE: deep layer, VD: very deep layer.

waters (Urbach et al., 2001; De Wever et al., 2005; Breuker et al., 2013; Kurilkina et al., 2016; Li et al., 2018). Anaerolineaceae has been described primarily as a group of anaerobic bacteria, but the description of this family was based mainly on mesophilic bacteria from a thermophilic reactor (Yamada et al., 2006). Some members of this group have also been reported in marine sediments (Breuker et al., 2013). Therefore, it is possible, as shown here, that members of this family can most likely be aerobic. This is in accordance with previous studies which have identified this group (formerly classified within the green non-sulfur bacteria) in aerobic deep waters in Crater Lake and Lake Baikal (Urbach et al., 2001; Kurilkina et al., 2016).

It is necessary to study in more detail the physiological adaptations of microorganisms in the deep layers of inland aquatic ecosystems similar to Issyk Kul (e.g. Lake Titicaca and the Caspian Sea), which withstand aphotic 
conditions, downward salinity increase, low temperatures, high hydrostatic pressure, but the increased availability of oxygen. Groups inhabiting this ecosystem, such as Anaerolineaceae, should present very particular physiological and ecological characteristics that deserve more attention (Mcllroy et al., 2017). It has also been suggested that physiological adaptations to depth could be accompanied by changes at the genomic level, including larger genome size, higher genomic GC content and proteins with higher nitrogen but lower carbon content (Mende et al., 2017).

Besides, it would be necessary to determine whether a hydrostatic pressure at $600 \mathrm{~m}$ in Lake Issyk Kul would be sufficient to trigger some proposed adaptation mechanisms such as increasing the proportion of unsaturated fatty acids in membrane phospholipids (Delong and Yayanos, 1985; DeLong and Yayanos, 1986; Tamburini et al., 2013; Wannicke et al., 2015), systems for active transport of sugars (DeLong and Yayanos, 1987) and an increase in bacterial protein production (Somero, 1992; Wannicke et al., 2015). The occurrence of these abovementioned adaptation mechanisms may be somewhat theoretical; however, it deserves further studies considering that the highest alpha diversity values were found in the ecosystem's deepest part.

In conclusion, in this work, we demonstrate the effect of depth and salinity on the variations in the structure of bacterial communities along the vertical gradient in Lake Issyk Kul, which is consistent with previous studies (Koizumi et al., 2003; Bryant et al., 2012; Mestre et al., 2017; Wu et al., 2019). We highlight a high bacterial diversity in the lake's deepest layers, where microorganisms live in brackish waters, aphotic conditions, low temperatures, high hydrostatic pressure, but completely aerobic conditions. Chloroflexi and Planctomycetes' dominance in the deeper layers raises questions about their ecological and functional roles, which should be further explored taking the increasing anthropogenic and climatic pressures into account the lake is facing currently and in the future.

\section{Experimental procedures}

\section{Environmental variables and sampling}

The sampling and environmental measurements were carried out in Lake Issyk Kul, a mountain lake with an average altitude of $1609 \mathrm{~m}$ above sea level and a maximum depth of $702 \mathrm{~m}$. This lake occupies a closed basin of tectonic origin with a total area of $6280 \mathrm{~km}^{2}$ and is considered the second largest mountain lake in the world after Lake Titicaca in Bolivia. The lake expedition was carried out during the cruise of the RV Moltur from June 25th to July 1st, 2017. All sampling stations in the lake and its tributaries are shown in Fig. 1. In total, 12 tributaries in the Southern and Eastern parts of the lake were sampled in triplicates at the well-mixed water column's surface. Triplicate samples from each tributary $(n=12)$ were pooled, and then a subsample of 0.5-2 L depending on the suspended matter concentration was filtered for DNA extraction (see below). We set 17 sampling points in the lake (one to five different depths each; Suppl. Table 1) and, in total, analysed 43 water samples. Sampling and measurement of physical and chemical variables were performed only from lake water samples using methods previously described (Zavialov et al., 2018). Briefly, water samples were taken using HydroBios $5 \mathrm{~L}$ Niskin bottles at all stations at different depth levels from the surface to the bottom. Depth was measured using a digital sounder (model LMS-350, Lowrance). Profiles of temperature, electric conductivity and fluorescence were taken with the CTD-probe SeaBird 19plus (Sea-Bird Scientific, USA). Oxygen profiles were taken with the fast-response oxygen optode Rinko-I (JFE Advantech, Japan). Salinity was calculated from temperature, electrical conductivity and pressure using the empirical formula for the Lake Issyk Kul ionic composition proposed by Peeters et al. (2003). Chemical determinations were performed in the laboratory using standard techniques; Winkler method for oxygen; the potentiometric method for $\mathrm{pH}$; titration method for alkalinity; colorimetric assay method for phosphates, silicates, nitrates, nitrites and carbon $\left(\mathrm{CO}_{2}, \mathrm{CO}_{3}\right.$ (carbon trioxide), $\mathrm{pCO}_{2}$ ) in different carbonate equilibria (Suppl. Fig. 1).

\section{Molecular analyses}

Samples were immediately filtered on board after retrieval of the Niskin bottle. The water samples were filtered through $0.22 \mu \mathrm{m}$ Sterivex® filters (EMD Millipore, Germany) connected to a peristaltic pump (EMD Millipore) to concentrate bacteria and subsequently stored at $-20^{\circ} \mathrm{C}$. DNA was extracted from $0.22 \mu \mathrm{m}$ Sterivex filters using the QIAamp DNA mini kit (Qiagen, Germany) following tissue protocol with some modifications. Briefly, the filters were cut into pieces and put into a $2 \mathrm{ml}$ tube. A mix of zirconium beads and $360 \mu \mathrm{l}$ of buffer ATL was added and vortexed for $5 \mathrm{~min}$ at $3000 \mathrm{rpm}$ in an Eppendorf MixMate ${ }^{\circledR}$ (Eppendorf, Germany). Proteinase $\mathrm{K}\left(>600 \mathrm{mAU} \mathrm{ml}^{-1}, 40 \mu \mathrm{l}\right)$ was added and incubated at $57^{\circ} \mathrm{C}$ for $1 \mathrm{~h}$. After centrifugation for $1 \mathrm{~min}$ at $11000 \mathrm{rpm}$, the supernatant was transferred to a new $2 \mathrm{ml}$ tube, and extraction was performed following the manufacturer's protocol. PCR, library preparation and sequencing were done by LGC Genomics (Berlin, Germany). Briefly, the V4-V5 region was amplified using primers 515F-Y/926R (Parada et al., 2016), followed by library preparation $(2 \times 300 \mathrm{bp})$ and sequencing on a MiSeq Illumina 
platform. Sequences were quality checked and analysed using version 1.12 of the DADA2 pipeline (Callahan et al., 2016). This process resulted in an ASV table, a higher-resolution analog of the traditional OTU table, which records the number of times each exact ASV was observed in a sample. The taxonomy assignment was performed by comparing sequences against the SILVA reference database v132 (Quast et al., 2013). The NCBI GenBank BLAST tool was also used to provide higher taxonomic resolution to some abundant ASVs poorly classified with SILVA. Global singletons were removed. Samples with low sequencing depth $(<3800$ sequences, $n=3$ ) were also discarded from the analysis. After these processes, we obtained 1790675 sequences and 4904 bacterial ASVs. The average number of sequences per sample was 24470 ranging from 3435 to 82992 . The sequence data were deposited in GenBank (https://www. ncbi.nlm.nih.gov/sra/PRJNA629986) under the SRA accession numbers SAMN14816440-SAMN14816494.

\section{Statistical analysis}

The statistical analyses and their visualization were performed in the $\mathrm{R}$ Project statistical program (R-CoreTeam, 2019), using the Rstudio interface v3.6.0. To better determine the effects of continuous variables on bacterial populations, we performed the binning of these variables. Binning is a data processing technique where the original values are grouped into intervals. The $n$ observations into $k$ clusters are done using the $k$ means algorithm, an unsupervised machine learning method. Each observation belongs to the cluster with the nearest mean. We used package dlookr v0.3.13 (Ryu, 2020) to perform the binning of variable depth and a semisupervised method for variable salinity, based on changes in the relative abundance cyanobacteria. The NDMS and PERMANOVA analyses were generated with package Vegan v2.5-6 (Oksanen et al., 2020). For this purpose, the ASV table was transformed into a table of relative abundances with the function decostand. The NDMS was represented in a two-dimensional plot based on a Bray-Curtis similarity matrix. The statistical significance of the effects of the different variables on the bacterial community composition was calculated using the adonis2 function with 999 permutations. The $p$-values of the pairwise comparisons were estimated with the pairwise. adonis function and adjusted with the Bonferroni method.

We applied random forest models to identify the critical environmental parameters affecting the relative abundance of the seven most abundant bacterial phyla utilizing package randomForest $v$ 4.6-14 (Liaw and Wiener, 2002). The degree of importance of each predictor variable was determined by quantifying the effect of its removal on the model's accuracy across 10001 trees, measured by the percentage increase in mean squared error. The model significance was tested with 1000 permutations using package rfUtilities $\vee$ 2.1-5 (Evans and Murphy, 2019). We used repeated k-fold cross-validation to estimate the model performance using the package caret v 6.0-86 (Kuhn, 2020). This cross-validation method was selected for its low bias and high reliability (Burman, 1989; Borra and Di Ciaccio, 2010; Kuhn and Johnson, 2013). Briefly, it randomly divides the data into 10 blocks of roughly equal size, and the model is trained 10 times, each time leaving out one of the subsets from the training, which is used to compute the prediction error. The whole process is repeated with different random splits, and the predictions are summarized into the root mean squared error.

Random forest models were applied to identify the critical environmental factors affecting the community's richness (number of trees $=10001$ ). To assess model fit, repeated 10 -fold cross-validation and permutation tests were also used. Then, the relationships between these environmental variables and bacterial family richness were explored with GAM, using packages mgcv v 1.8-31 and mgcViz $\vee$ 0.1.6 (Wood and Wood, 2015; Fasiolo et al., 2019). Kruskal-Wallis tests by rank and MannWhitney tests were used for estimating statistical differences within the intervals of each variable.

\section{Acknowledgements}

We are deeply thankful to the crew of the RV Moltur and the scientific team of the Shirshov Institute of Oceanology, Moscow, for assistance with fieldwork. The fieldwork was supported by Russian Foundation for Basic Research and Russian Geographic Society through their joint Grant No. 17-05-41043. POZ was supported by Ministry of Higher Education and Science of Russia through State Assignment Theme 0149-2019-003. GK and HPG were supported by the German Research Foundation (DFG Projects KI 853-16/1, Ki 853-13/1, GR1540/25-1 and GR1540/29-1).

\section{Author Contributions}

Conceptualization: H.P.G., G.K. and K.R.-J. Performing the research: L.G., P.O.Z., S.A., G.K. and H.P.G. Contributing new tools or methods: K.R.-J., A.A.L., F.Q.-P., J.A.-S., B.D-D. Analysing data: K.R.-J., A.A.L., F.Q.-P., J.A.-S., B.D.-D., L.G. Draft: K.R.-J., H.P.G., A.A.-L., F.Q.-P., J.A.-S., B.D.-D. Review \& Editing: all authors. All authors gave final approval for publication.

\section{References}

Baetov, R. (2005) Lake Issyk-Kul. In Managing Lakes and Their Basins for Sustainable Future. Kusatsu, Japan: 
International Lake Environment Committee Foundation, pp. 193-204.

Bel'kova, N.L., Parfenova, V.V., Kostornova, T.Y., Denisova, L.Y., and Zaichikov, E.F. (2003) Microbial biodiversity in the water of Lake Baikal. Microbiology 72: 203-213.

Borra, S., and Di Ciaccio, A. (2010) Measuring the prediction error. A comparison of cross-validation, bootstrap and covariance penalty methods. Comput Stat Data Anal 54: 2976-2989.

Breuker, A., Stadler, S., and Schippers, A. (2013) Microbial community analysis of deeply buried marine sediments of the New Jersey shallow shelf (IODP Expedition 313). FEMS Microbiol Ecol 85: 578-592.

Bryant, J.A., Stewart, F.J., Eppley, J.M., and Delong, E.F. (2012) Microbial community phylogenetic and trait diversity declines with depth in a marine oxygen minimum zone. Ecology 93: 1659-1673.

Burman, P. (1989) A comparative study of ordinary crossvalidation, $v$-fold cross-validation and the repeated learning-testing methods. Biometrika 76: 503-514.

Callahan, B.J., McMurdie, P.J., Rosen, M.J., Han, A.W., Johnson, A.J.A., and Holmes, S.P. (2016) DADA2: highresolution sample inference from Illumina amplicon data. Nat Methods 13: 581-583.

Callieri, C. (2008) Picophytoplankton in freshwater ecosystems: the importance of small-sized Phototrophs. Freshw Rev 1: 1-28.

Cottrell, M.T., and Kirchman, D.L. (2003) Contribution of major bacterial groups to bacterial biomass production (thymidine and leucine incorporation) in the Delaware estuary. Limnol Oceanogr 48: 168-178.

De Wever, A., Muylaert, K., Van der Gucht, K., Pirlot, S., Cocquyt, C., Descy, J.-P., et al. (2005) Bacterial community composition in Lake Tanganyika: vertical and horizontal heterogeneity. Appl Environ Microbiol 71: 5029-5037.

DeLong, E.F., Preston, C.M., Mincer, T., Rich, V., Hallam, S. J., Frigaard, N.U., et al. (2006) Community genomics among stratified microbial assemblages in the ocean's interior. Science 311: 496-503.

Delong, E.F., and Yayanos, A.A. (1985) Adaptation of the membrane lipids of a deep-sea bacterium to changes in hydrostatic pressure. Science 228: 1101-1103.

DeLong, E.F., and Yayanos, A.A. (1986) Biochemical function and ecological significance of novel bacterial lipids in deep-sea procaryotes. Appl Environ Microbiol 51: 730-737.

DeLong, E.F., and Yayanos, A.A. (1987) Properties of the glucose transport system in some deep-sea bacteria. Appl Environ Microbiol 53: 527-532.

Dodds, W.K., and Whiles, M.R. (2020) Chapter 7 - Lakes and reservoirs: physiography. In Aquatic Ecology, 3rd ed. Dodds, W.K., and Whiles, M.R.B.T.-F.E. (eds); London: Academic Press, pp. 155-187.

Eraslan, G., Avsec, Ž., Gagneur, J., and Theis, F.J. (2019) Deep learning: new computational modelling techniques for genomics. Nat Rev Genet 20: 389-403.

Evans, J.S., Murphy, M.A. (2018). rfUtilities. R package version 2.1-3. https://cran.r-project.org/package=rfUtilities.
Fasiolo, M., Nedellec, R., Goude, Y., and Wood, S.N. (2019) Scalable visualization methods for modern generalized additive models. J Comput Graph Stat 29: 1-9.

Garcia, S.L., Salka, I., Grossart, H., and Warnecke, F. (2013) Depth-discrete profiles of bacterial communities reveal pronounced spatio-temporal dynamics related to lake stratification. Environ Microbiol Rep 5: 549-555.

Giralt, S., Julià, R., Klerkx, J., Riera, S., Leroy, S., Buchaca, T., et al. (2004) 1,000-year environmental history of Lake Issyk-Kul. In Dying and Dead Seas Climatic Versus Anthropic Causes, Dordrecht: Springer, pp. 253-285.

Glöckner, F.O., Zaichikov, E., Belkova, N., Denissova, L., Pernthaler, J., Pernthaler, A., and Amann, R. (2000) Comparative 16S rRNA analysis of lake bacterioplankton reveals globally distributed phylogenetic clusters including an abundant group of actinobacteria. Appl Environ Microbiol 66: 5053-5065.

Herlemann, D.P.R.R., Labrenz, M., Jürgens, K., Bertilsson, S., Waniek, J.J., and Andersson, A.F. (2011) Transitions in bacterial communities along the $2000 \mathrm{~km}$ salinity gradient of the Baltic Sea. ISME J 5: 1571-1579.

Hofer, M., Peeters, F., Aeschbach-Hertig, W., Brennwald, M., Holocher, J., Livingstone, D.M., et al. (2002) Rapid deep-water renewal in Lake Issyk-Kul (Kyrgyzstan) indicated by transient tracers. Limnol Oceanogr 47: 1210-1216.

Kan, J., Evans, S.E., Chen, F., and Suzuki, M.T. (2008) Novel estuarine bacterioplankton in rRNA operon libraries from the Chesapeake Bay. Aquat Microb Ecol 51: 55-66.

Kirchman, D.L., Dittel, A.I., Malmstrom, R.R., and Cottrell, M. T. (2005) Biogeography of major bacterial groups in the Delaware Estuary. Limnol Oceanogr 50: 1697-1706.

Koizumi, Y., Kojima, H., and Fukui, M. (2003) Characterization of depth-related microbial community structure in lake sediment by denaturing gradient gel electrophoresis of amplified 16S rDNA and reversely transcribed 16S rRNA fragments. FEMS Microbiol Ecol 46: 147-157.

Kuhn, M. (2020) caret: Classification and Regression Training. R package version 6.0-86. https://CRAN.R-project. org/package=caret

Kuhn, M., and Johnson, K. (2013) Applied Predictive Modeling. New York: Springer.

Kurilkina, M.I., Zakharova, Y.R., Galachyants, Y.P., Petrova, D.P., Bukin, Y.S., Domysheva, V.M., et al. (2016) Bacterial community composition in the water column of the deepest freshwater Lake Baikal as determined by next-generation sequencing. FEMS Microbiol Ecol 92: fiw094.

Li, X., Yuan, Y., Yuan, Y., Bi, Z., Liu, X., Huang, Y., et al. (2018) Effects of salinity on the denitrification efficiency and community structure of a combined partial nitritationanaerobic ammonium oxidation process. Bioresour Technol 249: 550-556.

Liaw, A., and Wiener, M. (2002) Classification and regression by randomForest. $R$ News 2: 18-22.

Mcllroy, S.J., Kirkegaard, R.H., Dueholm, M.S., Fernando, E., Karst, S.M., Albertsen, M., and Nielsen, P. H. (2017) Culture-independent analyses reveal novel Anaerolineaceae as abundant primary fermenters in 
anaerobic digesters treating waste activated sludge. Front Microbiol 8: 1134.

Mende, D.R., Bryant, J.A., Aylward, F.O., Eppley, J.M., Nielsen, T., Karl, D.M., and DeLong, E.F. (2017) Environmental drivers of a microbial genomic transition zone in the ocean's interior. Nat Microbiol 2: 1367-1373.

Mestre, M., Ferrera, I., Borrull, E., Ortega-Retuerta, E., Mbedi, S., Grossart, H.P., et al. (2017) Spatial variability of marine bacterial and archaeal communities along the particulate matter continuum. Mol Ecol 26: 6827-6840.

Newton, R.J., Jones, S.E., Eiler, A., McMahon, K.D., and Bertilsson, S. (2011) A Guide to the Natural History of Freshwater Lake Bacteria. Microbiol Mol Biol Rev 75: 14-49.

Oksanen, J., Blanchet, F.G., Friendly, M., Kindt, R., Legendre, P., McGlinn, D., et al. (2020) vegan: Community Ecology Package (R package version 2.5-6).

Padisák, J., Barbosa, F.A.R., Koschel, R., and Krienitz, L. (2003) Deep layer cyanoprokaryota maxima in temperate and tropical lakes. Arch Für Hydrobiol Beih Adv Limnol 58: 175-199.

Padisák, J., Scheffler, W., Koschel, R., and Krienitz, L. (2004) Seasonal patterns and interannual variability of phytoplankton in Lake Stechlin. Berichte Des IGB 2004: 105-116.

Parada, A.E., Needham, D.M., and Fuhrman, J.A. (2016) Every base matters: assessing small subunit rRNA primers for marine microbiomes with mock communities, time series and global field samples. Environ Microbiol 18: 1403-1414.

Peeters, F., Finger, D., Hofer, M., Brennwald, M., Livingstone, D.M., and Kipfer, R. (2003) Deep-water renewal in Lake Issyk-Kul driven by differential cooling. Limnol Oceanogr 48: 1419-1431.

Peter, H., and Sommaruga, R. (2016) Shifts in diversity and function of lake bacterial communities upon glacier retreat. ISME J 10: 1545-1554.

Qu, K., Guo, F., Liu, X., Lin, Y., and Zou, Q. (2019) Application of machine learning in microbiology. Front Microbiol 10: 827.

Quast, C., Pruesse, E., Yilmaz, P., Gerken, J., Schweer, T., Yarza, P., et al. (2013) The SILVA ribosomal RNA gene database project: improved data processing and webbased tools. Nucleic Acids Res 41: D590-D596.

R-Core-Team. (2019) R: A Language and Environment for Statistical Computing.

Rojas-Jimenez, K., Rieck, A., Wurzbacher, C., Jürgens, K., Labrenz, M., and Grossart, H.-P. (2019) A salinity threshold separating fungal communities in the Baltic Sea. Front Microbiol 10: 680.

Romanovsky, V.V. (2002) Water level variations and water balance of Lake Issyk-Kul. In Lake Issyk-Kul: Its Natural Environment: Dordrecht: Springer, pp. 45-57.

Ryu, C. (2020) dlookr: Tools for Data Diagnosis, Exploration, Transformation.

Savvaitova, K., and Petr, T. (1992) Lake Issyk-kul, Kirgizia. Int J Salt Lake Res 1: 21-46.

Selmeczy, G.B., Tapolczai, K., Casper, P., Krienitz, L., and Padisák, J. (2016) Spatial-and niche segregation of DCMforming cyanobacteria in Lake Stechlin (Germany). Hydrobiologia 764: 229-240.
Simon, M., Glöckner, F.O., and Amann, R. (1999) Different community structure and temperature optima of heterotrophic picoplankton in various regions of the Southern Ocean. Aquat Microb Ecol 18: 275-284.

Somero, G. (1992) Adaptations to high hydrostatic pressure. Annu Rev Physiol 54: 557-577.

Tamburini, C., Boutrif, M., Garel, M., Colwell, R.R., and Deming, J.W. (2013) Prokaryotic responses to hydrostatic pressure in the ocean - a review. Environ Microbiol 15: 1262-1274.

Tang, X., Xie, G., Shao, K., Bayartu, S., Chen, Y., and Gao, G. (2012) Influence of salinity on the bacterial community composition in Lake Bosten, a large Oligosaline Lake in arid northwestern China. Appl Environ Microbiol 78: 4748-4751.

Tang, X., Xie, G., Shao, K., Dai, J., Chen, Y., Xu, Q., and Gao, G. (2015) Bacterial community composition in oligosaline lake Bosten: low overlap of betaproteobacteria and bacteroidetes with freshwater ecosystems. Microbes Environ 30: 180-188.

Urbach, E., Vergin, K.L., Young, L., Morse, A., Larson, G.L., and Giovannoni, S.J. (2001) Unusual bacterioplankton community structure in ultra-oligotrophic Crater Lake. Limnol Oceanogr 46: 557-572.

Verpoorter, C., Kutser, T., Seekell, D.A., and Tranvik, L.J. (2014) A global inventory of lakes based on highresolution satellite imagery. Geophys Res Lett 41: 6396-6402.

Wannicke, N., Frindte, K., Gust, G., Liskow, I., Wacker, A., Meyer, A., and Grossart, H.P. (2015) Measuring bacterial activity and community composition at high hydrostatic pressure using a novel experimental approach: a pilot study. FEMS Microbiol Ecol 91: fiv036.

Wilhelm, L., Singer, G.A., Fasching, C., Battin, T.J., and Besemer, K. (2013) Microbial biodiversity in glacier-fed streams. ISME J 7: 1651-1660.

Wood, S., and Wood, M.S. (2015) Package 'mgcv.' R Package Version 1: 29.

Wu, K., Zhao, W., Wang, Q., Yang, X., Zhu, L., Shen, J., et al. (2019) The relative abundance of benthic bacterial phyla along a water-depth gradient in a plateau Lake: physical, chemical, and biotic drivers. Front Microbiol 10: 1521.

Yamada, T., Sekiguchi, Y., Hanada, S., Imachi, H., Ohashi, A., Harada, H., and Kamagata, Y. (2006) Anaerolinea thermolimosa sp. nov., Levilinea saccharolytica gen. nov., sp. nov. and Leptolinea tardivitalis gen. nov., sp. nov., novel filamentous anaerobes, and description of the new classes Anaerolineae classis nov. and Caldilineae classis nov. in the bacterial phylum Chloroflexi. Int $J$ Syst Evol Microbiol 56: 1331-1340.

Zavialov, P.O., Izhitskiy, A.S., Kirillin, G.B., Khan, V.M., Konovalov, B.V., Makkaveev, P.N., et al. (2018) New profiling and mooring records help to assess variability of Lake Issyk-Kul and reveal unknown features of its thermohaline structure. Hydrol Earth Syst Sci 22: 6279-6295. 


\section{Supporting Information}

Additional Supporting Information may be found in the online version of this article at the publisher's web-site:

Supplementary Table 1. Locations and depths sampled in Lake Issyk Kul, Kyrgyzstan

Supplementary Table 2. Results of the statistical analysis where the structure of the microbial communities is compared between depth layers and salinity levels. The comparison was performed using PERMANOVA. Asterisks indicate significant differences.
Supplementary Fig. 1. Box plots of the measured environmental variables at different points of Lake Issyk Kul, by depth layers.

Supplementary Fig. 2. Relative abundance of the main bacterial groups in Lake Issyk Kul, shown in terms of the number of ASVs and number of sequences.

Supplementary Fig. 3. Temperature (black), dissolved oxygen (red), and fluorescence profiles in the upper $300 \mathrm{~m}$ of the central part of Issyk-Kul (18b in Fig. 1). 